\title{
Effectiveness of Academic Detailing on Breast Cancer Screening among Primary Care Physicians in an Underserved Community
}

\author{
Sherri Sheinfeld Gorin, PhD, Alfred R. Ashford, MD, Rafael Lantigua, MD, \\ Ashfaque Hossain MBB, MPH, Manisha Desai, PhD, Andrea Troxel, ScD, and \\ Donald Gemson, MD
}

Background: Urban minority groups, such as those living in northern Manhattan and the South Bronx, are generally underserved with regard to breast cancer prevention and screening practices. Primary care physicians are critical for the recommendation of mammography and clinical breast examinations to their patients.

Design: Two medically underserved communities were matched and block randomized. The aim of the study was to assess the efficacy of academic detailing in increasing recommendations for breast cancer screening in community-based primary care physicians.

Setting/Participants: Ninety-four primary care community-based (ie, not hospital-based) physicians in northern Manhattan were compared with $\mathbf{7 4}$ physicians in the South Bronx who received no intervention.

Intervention: Intervention participants received multicomponent physician-directed education, academic detailing, using the American Cancer Society guidelines for the early detection of breast cancer.

Main Outcome Measures: We administered interviews to ask about primary care physicians' recommendation of mammography and clinical breast examination. They were also queried about their knowledge of major risk factors and perceived barriers to breast cancer screening. We conducted medical audits of 710 medical charts 2 years before and after the intervention.

Results: Using a mixed models linear analysis, we found a statistically significant intervention effect on the recommendation of mammography and clinical breast examination (according to medical audit) by female patients age 40 and over. Intervention group physicians correctly identified significantly more risk factors for breast cancer, and significantly fewer barriers to practice, than did comparison physicians.

Conclusions: We found some evidence of improvement in breast cancer screening practices due to academic detailing among primary care physicians practicing in urban underserved communities. ( $\mathrm{J}$ Am Board Fam Med 2006;19:110-21.)

Although the use of breast cancer screening has risen considerably over the past 10 years, the rates among African American and Hispanic women still fall behind those of white women. ${ }^{1}$ This difference is due, in part, to variations in physician screening behaviors, ${ }^{2}$ particularly among underserved, low income patients. ${ }^{3}$ Disparities in screening contrib-

Submitted 23 November 2004; revised 17 September 2005; accepted 23 September 2005.

From the Departments of Epidemiology (SSG), Sociomedical Sciences (DG), and Biostatistics (MD), Mailman School of Public Health, Teachers College Department of Health and Social Behavior (SSG), Columbia University, New York, NY; Department of Medicine (ARA, RL) and Herbert Irving Comprehensive Cancer Center (SSG, ARA, RL, MD, DG), College of Physicians and Surgeons, Columbia University, New York, NY; Harlem Hospital Center (ARA), New York, NY; and Department of Biostatistics and Epidemiology (AT), University of Pennsylvania, School of Medicine, Philadelphia, PA. ute to increased morbidity and age-adjusted mortality from breast cancer among African American women relative to non-Hispanic whites. ${ }^{4-8}$

Studies have found that clinical practice guidelines have had limited success in influencing physician behaviors. ${ }^{9-13}$ But, two recent meta-analyses have highlighted the importance of physician recommendation to reducing these disparities. ${ }^{2,14}$

Funding: This study was funded by the National Cancer Institute (R25 CA66882).

An earlier version of this paper was presented in part at the Annual Meeting of the American Society of Preventive Oncology, 10 March 2002, in Bethesda, MD.

Conflict of interest: none declared.

Corresponding author: Sherri Sheinfeld Gorin, $\mathrm{PhD}, \mathrm{Co}-$ lumbia University, 954, 525 West 120th Street, Mailbox 239, New York, NY 10027 (E-mail: ssg19@columbia.edu). $\mathrm{AH}$ is deceased. 
Academic detailing entails a brief face-to-face intervention with the physician, repeated at periodic intervals. Detailers also share materials and approaches that are tailored to the physician's barriers to screening. Traditionally employed by pharmaceutical companies to promote prescription drug uptake among physicians, academic detailing has been found to be effective in many studies in which it has been evaluated. ${ }^{15-26}$

Some of these studies focus exclusively on prescribing (13 of the 18 studies cited by Hulscher et $\mathrm{al}^{27}$ ), have negative findings, ${ }^{28,29}$ or are inconclusive. ${ }^{30,31}$ These mixed findings highlight the need for more study of the impact of academic detailing for preventive services, particularly among medically underserved populations.

Academic detailing, as a multicomponent intervention, ${ }^{31,32}$ also includes techniques and tools that address office-based barriers to screening. Physician reminders (eg, chart flags, manual or computerized reminder systems ${ }^{33-36}$ ) and multilingual, low literacy patient education materials, ${ }^{37}$ among other components, have demonstrated increased breast, ${ }^{22}$ cervical $^{38}$ and colorectal $^{39,40}$ cancer screening in physicians' practices.

The intervention, academic detailing, relies on constructs from well-established theories to increase physician behavioral change. ${ }^{41}$ The theory of planned behavior (TPB $)^{42}$ posits the influence of focused attitudes and beliefs and social norms on breast cancer screening recommendation. By placing great importance on decision making, the TPB attempts to predict behaviors not entirely under individual control. Social cognitive theory (SCT) ${ }^{43}$ postulates that persons with high levels of selfefficacy and beliefs that positive outcomes will derive from screening will be most likely to recommend it. In SCT, social norms influence both cognitions and behavior. Fundamentally, academic detailing seeks to change physicians' attitudes and beliefs toward screening through persuasive communications, and to alter their cognitions through tailored feedback and reinforcement. Concomitantly, a prevention-oriented office context (eg, through trained staff) and cues in office procedures (eg, flagged medical charts) enrich the physician's memory for new information and reinforce behavioral patterns. ${ }^{44}$

The objective of this study was to assess the efficacy of academic detailing in increasing recommendations for breast cancer screening in a sample of community-based urban physicians compared with physicians in a similar community. To date, there have been no reported studies of the use of academic detailing as a method for increasing adherence to breast cancer screening guidelines among medically underserved African American and Hispanic populations.

\section{Subjects and Methods}

We matched the northern Manhattan (Harlem and Washington Heights) and South Bronx communities, areas with higher mortality from breast and other cancers, ${ }^{27,45,46}$ using US Census data, by the percentage of minority residents and those in poverty. These communities have been compared with a developing country, ${ }^{47}$ with residents who are generally poor (median household income $=\$ 23,656$ per year), with less education (15\% hold a bachelor's degree or higher), and primarily African American (33\%) or Hispanic (54\%). Approximately one-third $(31 \%)$ of the residents of these communities are foreign born (primarily from Latin America or the Caribbean/West Indies); 43\% speak only English at home, illustrative of their recent immigration to the United States. Only 51\% of their residents are employed; of those who are working, approximately one-quarter (26\%) hold managerial or professional positions. Of residents age 65 and older, $58 \%$ are disabled. Families in these communities have large families (median size, 3.4 persons).

We block randomized 48 of the physicians in the northern Manhattan community to the intervention condition, and those in the South Bronx to the comparison arm. We used block randomization at the level of the community to reduce clustering due to posited similarities among local primary care providers, and to decrease possible spillover effects between intervention and comparison physicians within these contiguous geographic areas.

\section{Participants}

To identify physicians working in northern Manhattan and the South Bronx, we collected licensing lists from New York State, directories from local hospitals, and names from our physician advisory board. We conducted door-to-door surveys of these communities to identify any additional physicians' offices. Of approximately 642 physicians in these communities who were contacted by telephone to assess eligibility, 359 devoted at least 50\% 
of their practice to primary care, were communitybased (ie, not hospital-based), and were not expecting to leave the area over the coming year, so met the study criteria. We enrolled 192 (53\%) of these physicians at baseline with a verbal consent. As is common in studies of organizations, ${ }^{49}$ we enrolled only the most senior fulltime (and thus the most influential) physician in the office. Physicians received Continuing Medical Education credits for their participation.

Both physician groups completed a baseline and a 12-month follow-up to assess changes in breast cancer knowledge, perceived barriers to screening, and the practice of early detection behaviors.

Of 192 eligible physicians, 87\% completed both a baseline and follow-up, yielding a final sample of 168 (94 intervention and 74 comparison physicians' offices). Two physicians retired, 5 moved, and 17 no longer practiced primary care, became too ill to practice, or refused to participate in the follow-up $(\mathrm{N}=24)$. The study was approved by the Institutional Review Board of Columbia University.

\section{Measures}

The 57-item questionnaire, administered in faceto-face interviews by project staff in 1997 to 1998 and 2001 to 2002, contained self-report items ${ }^{50,51}$ that assessed the physician's sociodemographic and medical practice characteristics, breast cancer prevention knowledge, attitudes/beliefs, and practices. Physicians' estimates of breast cancer screening practices were based on the binary answer (yes/no) to the following questions about mammography and clinical breast examination (CBE; by a health care provider): whether the physician conducts or recommends the procedure; if yes, the frequency of those screenings for asymptomatic women age 40 to 49 , and age 50 and over. One item assessed the recommendation of breast self-examination (BSE) by the patient. Physicians were asked about the perceived barriers to breast cancer screening, using 8 items, ${ }^{27,52}$ including; no medical indication, low yield, risk of radiation, resistance by patients, cost of the test, causing unnecessary worry for patients, the risk of false positives, and other (ie, patient discomfort, patient pain, prefer female provider, frequent lumps). The number of barriers was summed. To examine physicians' knowledge of other breast cancer prevention approaches, they were asked approximately 10 common risk factors, including: positive family history for breast cancer, for ovarian cancer, for breast and ovarian cancer; personal history of breast cancer, of ovarian cancer, of breast and ovarian cancer; increased age, late age at first pregnancy or nulliparity, early age at menarche, late age at menopause..$^{53-58}$ The number of correctly identified risk factors were summed to form a continuous measure.

Physician's self-reported age, number of years of medical practice, number of patient contacts per week, percentage of patients in the medical practice among different ethnic/racial and insurance subgroups (including the uninsured) were measured as continuous variables. Primary care physician's (PCP) graduation from a US or foreign medical school and race/ethnicity were categorical measures. These sociodemographic and medical practice measures have been associated with physician cancer screening behaviors. ${ }^{31,41}$

To measure the implementation process for office-based breast cancer prevention at follow-up, we administered a 12 -item subscale. ${ }^{49,50}$ The items were counted to create one "implementation score" per physician.

The instrument was pilot-tested on primary care physicians who were not included in the final study. Subscale items exploring the perceived barriers to cancer prevention and screening were moderately internally consistent (Cronbach's $\alpha=0.60$ to 0.73 ).

Audits were conducted on 710 charts at follow-up by 5 trained research assistants who were supervised by one of us (SSG), among a randomly selected subset of $15 \%$ of the physicians. We conducted medical audits on 13 offices each in the intervention and comparison groups, to reduce participant burden. Within the offices, using a table of random numbers, the trained abstractors who were blind to intervention group status, selected a sample of medical charts of women aged 40 and over who had not been diagnosed with breast cancer, with at least one documented visit to the physician over the past 2 years (median $=46$ charts). Each chart was abstracted, using a structured form (available from SSG), the 2 years before and after the intervention. Radiologist's reports of all mammograms were abstracted. We defined a recommendation for mammography and/or CBE either explicitly, with a notation in the chart (ie, a written referral for mammography, conduct of a CBE or a mammogram by a health care provider or from another screening center), or implicitly, with a radiologist's report of the findings from a mammo- 
gram. ${ }^{61}$ A mammogram or CBE was characterized as screening if the physician recorded "screening" as the purpose of the procedure, noted it on the referral, or if there were no relevant patient symptoms (eg, pain, nipple discharge) in the medical record at the time of the recommendation.

\section{Academic Detailing Intervention}

Ninety seven percent of the intervention physicians received 4 academic detailing visits with self-learning packets (ie, professionally designed print materials, scientific articles, and a targeted verbal script) from 2 Master's level health educators; the remaining 3 physicians received 3 face-to-face visits each over a 2-year period of time. Throughout, we highlighted the American Cancer Society (ACS) breast cancer screening recommendations for asymptomatic women, age 40 and over, as they are the most widely recognized guidelines in these local practices. At the time, the ACS recommendations included mammograms every year for women age 40 and older, CBEs for women ages 20 to 40 every 3 years, and CBEs every year for women age 40 and over. For women age 20 and over, the ACS recommended a monthly breast self-examination (BSE).

Academic detailing contacts with the physician were brief (average, 9.25 minutes). If the physician consented, the office-based breast cancer prevention materials (adapted from Ref. 59) were shared with the other staff as well.

To increase efficient contact with the intervention physicians, visits were supplemented by 6 dinner seminars; $46 \%$ of the intervention physicians attended. We also disseminated a newsletter to decrease attrition.

Before implementation, the academic detailing script and print materials were evaluated for face validity by a panel of physicians who served on an advisory board. For patient education, we used multilingual American Cancer Society materials that have been evaluated for readability. ${ }^{62}$

\section{Analytic Plan}

Differences between the sociodemographic, knowledge, attitude/belief, and screening factors by condition were each tested via $\chi^{2}$ analyses (or Mantel Haentzel $X^{2}$ for screening recommendations) or by an analysis of variance (ANOVA). The independent factors were further evaluated as confounds; those items found to be statistically significant $(P<$ $.05)$, and interaction terms, were tested simulta- neously for their effects on the rates of screening. The number of years the physician had been in practice was included in all multivariate models a priori.

As the knowledge of risk factors and barriers to screening were collected at the physician level, and were continuous measures, they were analyzed via a hierarchical multiple linear regression analysis, with the intervention term entered last. Standard diagnostic techniques were used to test for multicollinearity and the model performed favorably; similarly; a plot of the residuals revealed no problematic patterns.

Physicians' self-report data tend to over-estimate their screening behaviors. ${ }^{61,63-65}$ Therefore, we used the medical audit data to calculate the major study outcome, measured as the proportion of screened women to all women (age 40 and over) per physician. All multivariate analyses of the medical audit data, calculated as proportions, were conducted at the patient level using the mixed effects model GLIMMIX in SAS, ${ }^{66,67}$ with a random physician effect. This model was selected to account for clustering among patients within physicians' offices, improve power, enhance the flexibility to examine some patient-level covariates, and because of clinical interest. Goodness-of-fit statistics were examined to determine the adequacy of the model.

Missing data for the practice measures $(<5 \%)$ were imputed by the researchers with the mean value. ${ }^{68}$ When applicable, all p-values resulted from use of 2-sided tests.

\section{Results}

At baseline, the intervention $(\mathrm{N}=94)$ and comparison $(\mathrm{N}=74)$ physicians were similar by age, gender, race/ethnicity, number of years of practice, practice size (in number of patient contacts per week), patient racial/ethnic characteristics and the implementation score; fewer physicians in the comparison group graduated from an American medical school $(P<.0001)$, practiced with patients who have Medicaid and Medicare coverage $(P<.0001)$, and had managed care contracts $(P<.001)$ than physicians in the intervention group (see Table 1). More physicians in the comparison group saw patients with "other" payer sources (eg, self-pay) than intervention participants $(P<.0001)$. These sociodemographic and medical practice baseline differences were included as confounders in the multivariate analyses. 
Table 1. Sociodemographic and medical practice characteristics of the primary care physician sample at baseline $(\mathrm{N}=168)$

\begin{tabular}{|c|c|c|c|c|}
\hline & All & Intervention & Comparison & $\mathrm{N}$ \\
\hline Age, mean years $(\mathrm{SD})$ & $47(45)$ & $48(12)$ & $46(12)$ & 167 \\
\hline Female, \% & 31 & 28 & 36 & 168 \\
\hline African Americans/Hispanics, \% & 74 & 79 & 67 & 168 \\
\hline Graduate US medical school, \%* & 39 & 51 & 18 & 168 \\
\hline Number of years practice, mean (SD) & $16(12)$ & $16(12)$ & $15(11)$ & 167 \\
\hline Number of pat contacts/week & $80(75)$ & $80(36)$ & $75(29)$ & 163 \\
\hline $\begin{array}{l}\text { Insurance, \%‡ } \\
\text { Medicaid and Medicare, mean \% (SD)* } \\
\text { Private indemnity, mean \% (SD) } \\
\text { Managed care, mean \% (SD) } † \\
\text { Uninsured, mean \% (SD) } \\
\text { Other insurance, mean \% (SD)*\$ }\end{array}$ & $\begin{array}{l}40(31) \\
40(31) \\
21(31) \\
11(21) \\
13(31)\end{array}$ & $\begin{array}{r}47(31) \\
15(25) \\
27(34) \\
13(24) \\
6(20)\end{array}$ & $\begin{array}{r}30(28) \\
8(20) \\
12(23) \\
8(17) \\
23(42)\end{array}$ & $\begin{array}{l}151 \\
150 \\
151 \\
152 \\
154\end{array}$ \\
\hline Practice with non-Hispanic white patients, mean \% (SD) & $7(16)$ & $9(18)$ & $4(14)$ & 156 \\
\hline Implementation score, mean (SD)\| & $4.5(2.44)$ & $4.68(2.71)$ & $4.27(2.04)$ & 168 \\
\hline
\end{tabular}

${ }^{*} P<.0001$.

$\dagger P<.001$.

‡ Columns do not sum to $100 \%$ because of participant under-reporting or over-reporting.

$\$$ Columns do not sum to $100 \%$ because of participant under-reporting or over-reporting; other, eg, self-pay, Worker's Compensation. $\|$ Collected at followup only. The score is a total count of the following individual items: manual or computerized prompting or tracking of preventive services (eg, chart reminders or stickers), computerized reminders to patients for follow-up, pamphlets, wall posters, or printed materials for patient education, and/or performance targets, incentives, and feedback for breast cancer screening, whether office staff are involved in tracking or counseling women for breast cancer screening.

\section{Analyses of Physician Self-reported Knowledge of Risk Factors for Breast Cancer and Barriers to Screening}

Multiple linear regression analyses were conducted to evaluate the impact of the intervention on PCPs' knowledge of breast cancer risk factors and perceived barriers to breast cancer screening at follow-up relative to baseline (see Table 2). Covariates included whether the PCP attended a US (or foreign) medical school, knowledge of breast cancer risk factors, perceived barriers to breast cancer screening, number of years of practice, percentage of patients enrolled in managed care, percentage of patients enrolled in other insurance, and percentage of patients enrolled in Medicare or Medicaid.

The intervention group reported significantly more knowledge of breast cancer risk factors at follow-up than at baseline, compared with the physicians in the control group $(P<.01$, see Table 2$)$. Physicians in practices with more patients who received Medicare or Medicaid were less influenced in their knowledge of risk factors for breast cancer by the intervention than other PCPs $(P<.04)$. PCPs who could name more relevant risk factors at baseline could also identify more at follow-up $(P<$ .00001). The intervention group perceived fewer barriers to the practice of breast cancer screening at follow-up than at baseline, compared with physicians in the control group $(P<.00001$, see Table 2). PCPs who identified more barriers at baseline also identified more at follow-up $(P<.0001)$. These effects remained after the introduction of confounders.

\section{Medical Audit Findings on Breast Cancer Screening}

Repeated measures ANOVA analyses of the medical audit data on the use of mammography revealed a significant intervention effect for women age 40 and older compared with the control group (see Figure 1). There was no intervention effect for CBE recommendations to women age 40 and older (see Figure 2). Overall, we recorded only 16 chart notations for teaching or recommending BSE; these data were too few to analyze.

\section{Linear Mixed Model Analyses of Medical Audit Data on Screening Recommendations}

As patients were clustered within physician practices, linear mixed models with the physician as a random effect examined the relationships between the intervention and the comparison groups on the proportion of women recommended for screening over the past 2 years using medical audit data (see Table 3). Covariates in the model included whether 
Table 2. Multiple linear regression analysis of the effect of academic detailing on (1) knowledge of risk factors at post-test and (2) barriers to breast cancer screening $(\mathrm{N}=168$ for both)*

\begin{tabular}{|c|c|c|c|c|c|c|c|c|}
\hline & \multicolumn{4}{|c|}{$\begin{array}{l}\text { Effect of Academic Detailing on } \\
\text { Knowledge of Risk Factors at Post-test }\end{array}$} & \multicolumn{4}{|c|}{$\begin{array}{l}\text { Effect of Academic Detailing on } \\
\text { Barriers to Breast Cancer Screening }\end{array}$} \\
\hline & Beta† & $95 \%$ CI & $R^{2} \Delta \S$ & $P$ & Beta $\dagger$ & $95 \%$ CI $\neq$ & $R^{2} \Delta \S$ & $P$ \\
\hline $\begin{array}{l}\text { No. years of medical } \\
\text { practice }\end{array}$ & -0.10 & $-0.03,0.007$ & & .25 & -0.02 & $-2.75,2.65$ & & .81 \\
\hline Medical school & 0.08 & $-0.21,0.62$ & & .33 & -0.01 & $-0.90,0.78$ & & .89 \\
\hline $\begin{array}{l}\text { Percentage of patients } \\
\text { insured by Medicaid or } \\
\text { Medicare }\end{array}$ & -0.18 & $-0.02,0.00$ & & .04 & 0.05 & $-0.009,0.02$ & & .52 \\
\hline $\begin{array}{l}\text { Percentage of patients } \\
\text { insured by managed care }\end{array}$ & 0.03 & $-0.005,0.008$ & & .70 & -0.09 & $-0.02,0.005$ & & .24 \\
\hline $\begin{array}{l}\text { Baseline knowledge of risk } \\
\text { factors for breast cancer } \|\end{array}$ & 0.35 & $0.24,0.68$ & 0.18 & $<.00001$ & $\mathrm{n} / \mathrm{a}$ & & & \\
\hline $\begin{array}{l}\text { Baseline barriers to breast } \\
\text { cancer screeningपl }\end{array}$ & $\mathrm{n} / \mathrm{a}$ & & & & 0.60 & $0.44,0.77$ & 0.2 & $<.0001$ \\
\hline Intervention ${ }^{* *} \dagger \dagger^{\mathrm{f}, \mathrm{g}}$ & 0.23 & $-0.14,1.06$ & 0.04 & .01 & -0.48 & $-1.62,3.75$ & 0.13 & $<.00001$ \\
\hline
\end{tabular}

* Using self-report data, after completion of academic detailing intervention.

$\dagger$ Beta is the standardized regression coefficient, ie, a standardized measure of the change in outcome attributable to one predictor with the remaining predictors held constant. ${ }^{68}$

$\neq 95 \%$ confidence intervals

$\$ R^{2} \Delta$ is the change in the percentage of variation in the outcome explained by all of the predictors in the model. $R^{2} \Delta$ is for the full model including all of the listed factors except intervention.

\| Range, 1 to 7 .

II Range, 0 to 8.

** Intervention model with knowledge of breast cancer risk factors as outcome adjusted for baseline knowledge of breast cancer risk factors, number of years of practice, whether attended US medical school, follow-up barriers to breast cancer screening, percentage of patients enrolled in managed care, percentage of patients enrolled in Medicare or Medicaid, percentage of patients with other insurance, overall model, $P<.00001$.

$\dagger+$ Intervention model with barriers to breast cancer screening as outcome adjusted for baseline barriers to breast cancer screening, follow-up knowledge of breast cancer risk factors, number of years of practice, whether attended US medical school, percentage of patients enrolled in managed care, percentage of patients enrolled in Medicare or Medicaid, percentage of patients with other insurance, overall model, $P<.00001$

the PCP attended a US (or foreign) medical school, number of years of practice, baseline rates of mammography or CBE as appropriate to the outcome, follow-up knowledge of breast cancer risk factors, follow-up barriers to breast cancer screening, percentage of patients enrolled in managed care, percentage of patients enrolled in other insurance, and percentage of patients enrolled in Medicare or Medicaid.

PCPs who were assigned to the intervention condition were more likely to recommend mammograms to women age 40 and older at follow-up than control physicians $(P<.002$; see Table 3$)$. PCPs who recommended mammograms before the intervention were significantly more likely to recommend them at follow-up than were comparable physicians $(P<.0001)$. The smaller the percentage of women in a PCP's practice with Medicaid or Medicare, the more mammograms the physician recommended at follow-up $(P<.0001)$. Finally, the greater the PCP's knowledge of risk factors for breast cancer, the greater proportion of women age 40 and older recommended for mammography screening $(P<.0001)$. The covariates of number of years of practice (for CBE), percentage of patients in managed care, and the barriers to practice were deleted from the model because their contributions were null.

Similarly, PCPs who were assigned to the intervention condition were twice as likely to recommend CBEs to women age 40 and older at follow-up than were comparison physicians $(P<.002$; see Table 3). The smaller the percentage of women in a PCP's practice with Medicaid and Medicare relative to other insured women, the more CBEs the physician recommended at follow-up $(P<$ .0001). As with the findings for mammography recommendations, the greater the PCP's knowledge of risk factors for breast cancer, the greater proportion of women age 40 and older recommended for 


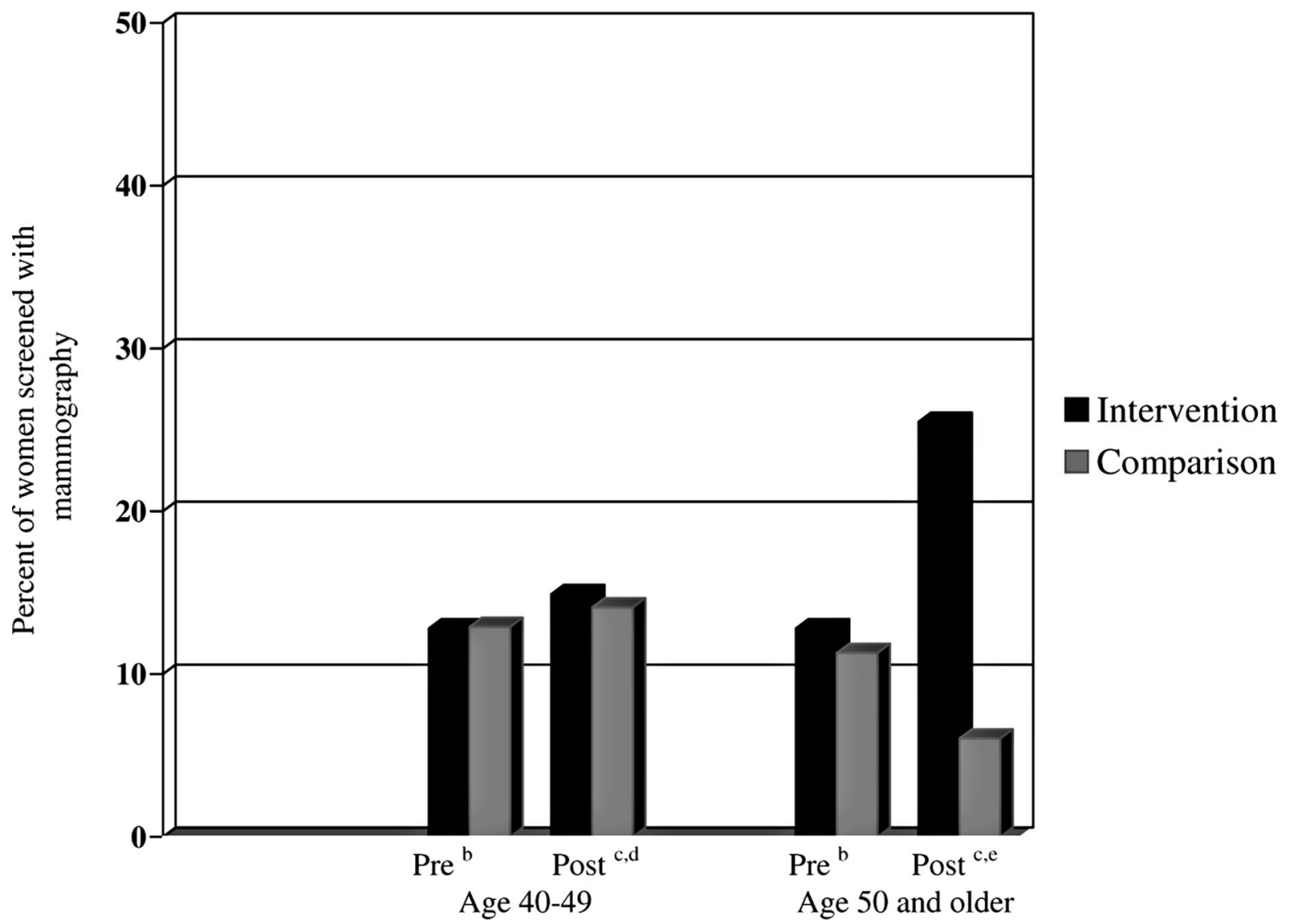

Figure 1. Effect of academic detailing on percentage of women recommended for screening with mammography using chart audit data: $b, 2$ years preintervention; $c$, at follow-up after completion of academic detailing intervention; $d$, repeated measures ANOVA $(P=.01) ; e$, repeated measures ANOVA $(P=.01)$.

CBE $(P<.0001)$. There was also a statistical trend toward more recommendations for CBE among PCPs who identified fewer barriers to screening than among comparable physicians $(P<.06)$. None of the other measured factors were associated with PCPs' CBE recommendations. The managed care factor was deleted from the model because of a null contribution. There were no statistically significant interactions in any of the tested models.

\section{Discussion}

Academic detailing seemed to increase primary care physicians' recommendations for mammography and $\mathrm{CBE}$ among women age 40 and older. The findings are strong and consistent using medical audit measures for mammography and CBE among women age 40 and older. The findings on the impact of academic detailing on preventive behavior among PCPs are also consonant with those from a recent randomized clinical trial ${ }^{26}$ that suc- cessfully increased recommendations for smoking cessation counseling among primary care physicians; the preventive aim, the modification of counseling skills, the sample of community-based physicians, and patient verification are notably similar, suggesting the strength of the result. The findings on increased CBE recommendations post-intervention are consistent with those from another study of the impact of physician office-based education on CBE for breast cancer screening, ${ }^{18}$ despite differences in the patient populations. The consistency of these results across several studies suggests robust findings.

The rates of mammography at follow-up are consistent with those from the National Health Interview Survey (NHIS) for African American and Hispanic women who dominate in these communities. ${ }^{69} \mathrm{CBE}$ rates are still below population-based comparisons from patients' self-report, ${ }^{1,70}$ however, perhaps due to under-notation in the medical 


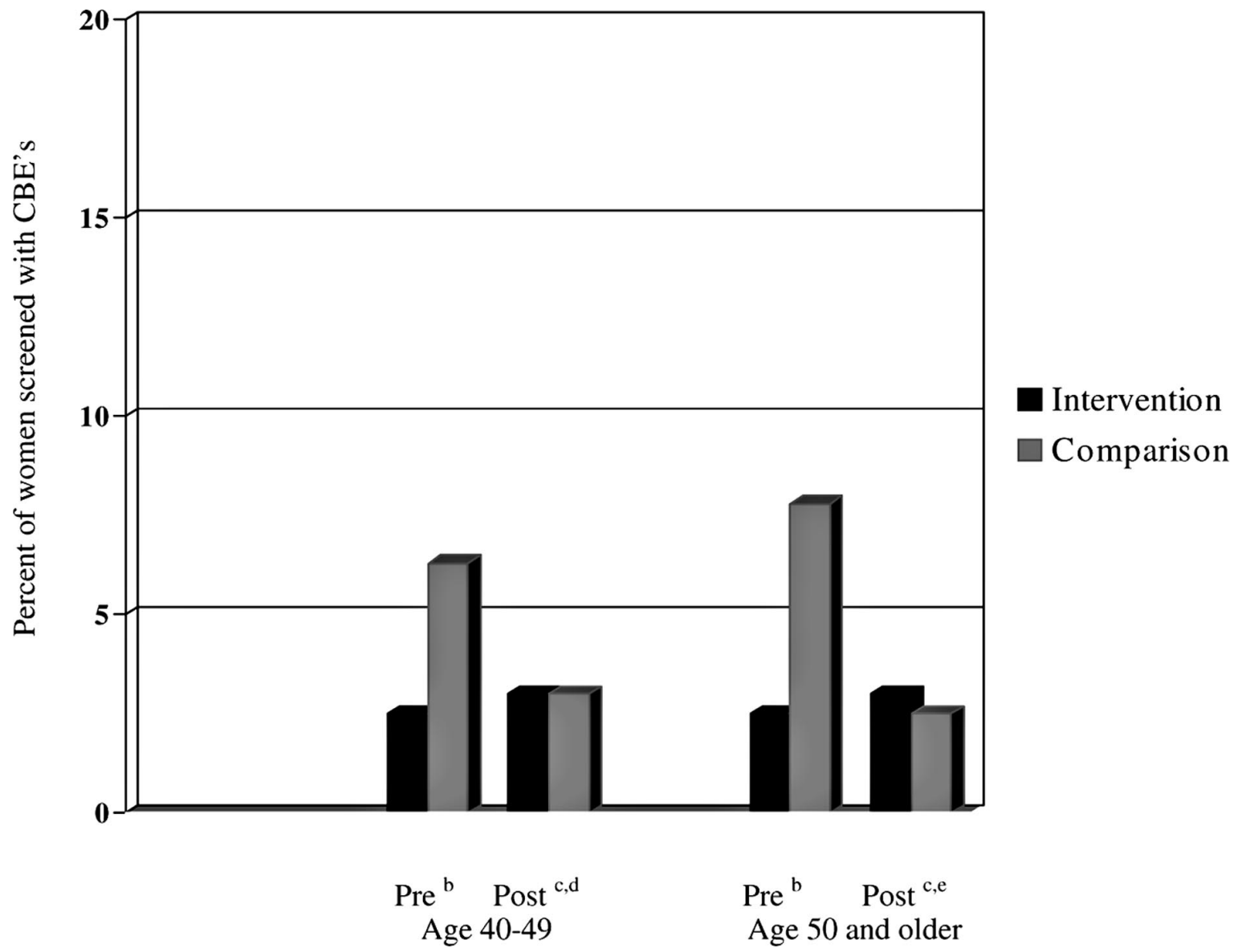

Figure 2. Effect of academic detailing on percentage of women recommended for screening with clinical breast examination (CBE) using chart audit data: $b, 2$ years preintervention; $c$, at follow-up after completion of academic detailing intervention; $d$, repeated measures ANOVA $(P=.98) ; e$, repeated measures ANOVA $(P=.95)$.

record and some ( $9 \%$ in our sample) referral to obstetricians and gynecologists for the procedure. As providers generally receive no additional payment for performing the $\mathrm{CBE},{ }^{71}$ and institutional performance standards for CBE are inconsistent, ${ }^{72}$ there are few incentives for the physician to record the activity in the medical record. Further, perhaps Medicaid or Medicare coverage influences the likelihood of PCP's breast cancer screening.

The intervention physicians correctly reported more risk factors for breast cancer, and fewer barriers to the practice of breast cancer screening than comparison physicians. Physicians' familiarity with screening guidelines, and their attitudes and beliefs toward testing seem critical to explaining their compliance with professional recommendations. ${ }^{73-76}$ Separate analyses of the self-report data revealed that the intervention reduces perceived patient resistance to, cost of, and worry about screening, even though the scientific controversies that surround mammography (ie, low yield, risks of false positives) remain barriers to physician screening recommendations. We found that office-based procedures (for review, see Ref. 32), although more common among intervention than comparison participants at follow-up, may be necessary, but not sufficient to effect breast cancer screening changes in these underserved communities.

Interestingly, the comparison physicians also increased their mammography screening recommendations to all eligible women from baseline to follow-up. These increases may reflect the effect of study participation that sensitized control PCPs to breast cancer screening. These increases may also reflect the burgeoning interest in breast cancer developed by advocacy groups, ${ }^{77}$ and both provider and patient attention to the national controversies about breast cancer screening ${ }^{78}$ during the intervention years of the late 1990s. 
Table 3. Linear mixed models analysis of the effect of academic detailing on physician recommendations for (1) mammography at follow-up and (2) clinical breast examination (CBE) at follow-up ( $=710$ for both)*

\begin{tabular}{|c|c|c|c|c|c|c|c|c|c|c|c|c|}
\hline & \multicolumn{6}{|c|}{$\begin{array}{c}\text { Effect of Academic Detailing on } \\
\text { Physician Recommendation of } \\
\text { Mammography at Follow-up }\end{array}$} & \multicolumn{6}{|c|}{$\begin{array}{l}\text { Effect of Academic Detailing on } \\
\text { Physician Recommendation of } \\
\text { CBE at Follow-up }\end{array}$} \\
\hline & Beta† & SE & $\mathrm{t}$ & OR & $95 \% \mathrm{CIS}$ & $P$ & Beta† & SE & $\mathrm{t}$ & OR $\ddagger$ & $95 \% \mathrm{CIS}$ & $P$ \\
\hline Years of practice $\|$ & & & & & & & -0.003 & 0.006 & -0.48 & & & .63 \\
\hline Medical school & 0.19 & 0.23 & 0.86 & & & .39 & -0.40 & 0.30 & -1.35 & & & .18 \\
\hline $\begin{array}{l}\text { Percentage of patients } \\
\text { insured by Medicaid or } \\
\text { Medicare }\end{array}$ & -0.03 & 0.006 & -4.47 & & & $<.0001$ & -0.04 & 0.007 & -5.26 & & & $<.0001$ \\
\hline Barriers to screening $\|$ & & & & & & & -0.48 & 0.26 & -1.87 & & & .06 \\
\hline $\begin{array}{l}\text { Knowledge of risk factors } \\
\text { for breast cancer }\end{array}$ & 1.32 & 0.23 & 5.79 & & & $<.0001$ & 1.62 & 0.24 & 6.83 & & & $<.0001$ \\
\hline Age ( 40 to $49, \geq 50$ ) & & & & 0.97 & $0.58,1.62$ & .91 & & & & 1.09 & $0.57,2.05$ & .80 \\
\hline $\begin{array}{l}\text { Baseline mammography } \\
\text { proportion }\end{array}$ & & & & 5.17 & $3.15,8.46$ & $<.0001$ & $\mathrm{n} / \mathrm{a}$ & & & & & \\
\hline Baseline CBE proportion & $\mathrm{n} / \mathrm{a}$ & & & & & & & & & 1.37 & $0.73,2.56$ & .33 \\
\hline Intervention $\mathbb{I}^{* *}$ & & & & 1.85 & $1.25,2.74$ & .002 & & & & 2.13 & $1.31,3.46$ & .002 \\
\hline
\end{tabular}

* Using medical audit data, after completion of academic detailing intervention; analyzed via GLIMMIX in SAS, to account for clustering of patients.

† Beta is the standardized regression coefficient, ie, a standardized measure of the change in outcome attributable to one predictor with the remaining predictors held constant. ${ }^{68}$

$\neq$ The reference is the control group.

$\$ 95 \%$ confidence intervals.

$\|$ The contribution of this factor was null so it was deleted from the model.

II Intervention model with mammography screening as outcome adjusted for baseline rates of recommendations for mammography screening, whether attended US medical school, follow-up knowledge of breast cancer risk factors, follow-up barriers to breast cancer screening, percentage of patients enrolled in Medicare or Medicaid, percentage of patients enrolled in other insurance.

** Intervention model with CBE as outcome adjusted for baseline CBE rates, number of years of practice, whether attended US medical school, follow-up knowledge of breast cancer risk factors, follow-up barriers to breast cancer screening, percentage of patients enrolled in Medicare or Medicaid, percentage of patients enrolled in other insurance.

Academic detailing is a moderate cost intervention (approximately $\$ 721.77$ per participant ${ }^{79}$ ); as a result, one large department of public health (in New York City) has implemented the intervention for several prevention approaches among primary care physicians city-wide. Nonetheless, the intervention may not be fiscally feasible in other communities. Through cooperative agreements, however, departments of public health may encourage pharmaceutical and insurance companies to incorporate health promotion messages into their existing detailing practices.

Although the study has strengths, it also has several limitations. The study used block randomization at the level of the community; analyses were conducted among physicians and patients; despite the acceptance of this design approach for prevention trials (eg, Collaborative group for COMMIT trials ${ }^{80}$ ) and the application of appropriate statistical approaches to the data analysis, unmeasured differences may have influenced outcomes. We ob- tained relatively high rates of physician study participation (comparable with Myers et $\mathrm{al}^{81}$ and higher than the $21 \%$ enrollment obtained among health plan-affiliated provider organizations to participate in a similar study of colorectal cancer screening by Ganz et $\mathrm{al}^{82}$ ), and audited the medical record to obtain the rates of physician screening recommendations. Further, chart audits demonstrate superior accuracy in capturing physician screening behaviors relative to self-report. ${ }^{83,84}$ Four sociodemographic or medical practice factors differentiated the intervention and control PCPs at baseline; they (notably, Medicare or Medicaid coverage, as mentioned earlier) may have confounded the relationship between study arm and CBE screening, in particular. These factors were included as covariates in all the multivariate analyses, and comparable testing was conducted in both groups, so that their impact on the outcomes could be examined directly, however. To reduce the respondent burden on these often turbulent urban 
offices, we collected medical audit data from a small subsample of physicians. The size of the audited subsample may limit the generalizability of the results. The audited offices were selected at random, and the rates for mammography are consonant with those found in a population-based household survey of the community, however. ${ }^{65,70}$ Although we used well-trained, blinded, closely supervised medical abstractors, they may have surmised the intervention group, thus biasing the findings.

The study suggests that this clinically based intervention, academic detailing, may increase screening recommendations among urban practices that are dominated by Hispanic and African American women, who are themselves more likely to die of breast cancer than are other sub-populations.

We thank Stefanie Jean Baptiste for assistance with data collection. We are grateful to Dr. Alfred I. Neugut for comments on an earlier version of the paper.

\section{References}

1. Bolen JC, Rhodes L, Powell-Griner EE, Bland SD, Holtzman D. State-specific prevalence of selected health behaviors, by race and ethnicity-behavioral risk factor surveillance system. MMWR 1997;49: (SS02):1-60.

2. Mandelblatt JS, Yabroff KR. Effectiveness of interventions designed to increase mammography use: a meta-analyis of provider-targeted strategies. Cancer Epidemiol Biomarkers Prev 1999;8:759-67.

3. Gemson DH, Elinson J, Messeri P. Differences in physician prevention practice patterns for white and minority patients. J Comm Health 1988;13:53-64.

4. McCord C, Freeman HP. Excess mortality in Harlem. N Engl J Med 1990;322:173-7.

5. Neugut AI, Timony D, Murray T. Colorectal cancer: differences between community and geographically distant patients seen in an urban medical center. Dis Colon Rectum 1991;34:64-8.

6. Freeman HP. Cancer in the socioeconomically disadvantaged. CA 1989;39:266-88.

7. Savage D, Lindenbaum J, Van Ryzin J, Struening E, Garrett TJ. Race, poverty, and survival in multiple myeloma. Cancer 1984;54:3085-94.

8. Dignam JJ. Differences in breast cancer prognosis among African-American and Caucasian women. CA 2000;50:50-64.

9. Greco PJ, Eisenberg JM. Changing physicians' practices. N Engl J Med 94;17:1271-3.

10. Wender RC. Cancer screening and prevention in primary care: obstacles for physicians. Cancer 1993; 72:1093-9.

11. McPhee SJ, Bird JA, Jenkins CNH, Fordham D.
Promoting cancer screening: a randomized, controlled trial of three interventions. Arch Intern Med 1989;149:1866-72.

12. Lomas J, Haynes RB. A taxonomy and critical review of tested strategies for the application of clinical practice recommendations: from "official" to "individual" clinical policy. Am J Prev Med 1988;4:77-84.

13. Haynes RB, Davis DA, McKibbon DA, Tugwell PA. Critical appraisal of the efficacy of continuing medical education. JAMA 1984;251:61-4.

14. Legler J, Meissner HI, Coyne C, Breen N, Chollette $\mathrm{V}$, Rimer BK. The effectiveness of interventions to promote mammography among women with historically lower rates of screening. Cancer Epidemiol Biomark Prev 2002;11:59-71.

15. Thomson O'Brien MA, Oxman AD, Davis DA, Haynes RB, Freemantle N, Harvey EL. Educational outreach visits: effects on professional practice and health care outcomes. Cochrane Database System Rev 2000;2:CD000409.

16. Schaffner $W$, Ray $W$, Federspiel CF, Miller WO. Improving antibiotic prescribing in office practice: a controlled trial of three educational methods. JAMA 983;250:1732-7.

17. Keys PW, Goetz CM, Keys PA, Sterchele JA, Snedden TM, Livengood BH. Computer-guided academic detailing as part of a drug benefit program. Am J Health-System Pharm 1995;52:2199-203.

18. Daly MB, Balshem M, Sands C, James J, Workman S, Engstrom PF. Academic detailing: a model for in-office CME. J Cancer Educ 1993;8:273-80.

19. Wyatt JC, Paterson-Brown S, Johanson R, Altman DG, Bradburn MJ, Fisk, NM. Randomised trial of educational visits to enhance use of systematic reviews in 25 obstetric units. BMJ 1998;317:1041-6.

20. Horowitz CR, Goldberg HI, Martin DP, et al. Conducting a randomized controlled trial of CQI and academic detailing to implement clinical guidelines. Joint Comm J Quality Improvement 1996;22:73450.

21. Dietrich AJ, Sox CH, Tosteson TD, Woodruff CB. Durability of improved physician early detection of cancer after conclusion of intervention support. Cancer Epidemiol Biomarkers Prev 1994;3:335-40.

22. Davis DA, Thompson MA, Oxman AD, Haynes RB. Changing physician performance: a systematic review of the continuing medical education strategies. JAMA 1995;274:700-5.

23. Leninger LS, Finn L, Dickey L, et al. An office system for organizing preventive services: a report by the American Cancer Society advisory group on preventive health care reminder systems. Arch Fam Med 1996;5:108-15.

24. Ashford AR, Neugut AI, Sheinfeld Gorin SN, et al. Effectiveness of community physician education for cancer screening, prevention, and treatment. Presented at 22nd Annual Meeting of the American 
Society of Preventive Oncology, Bethesda, MD, March 1998.

25. Benincasa TA, King ES, Rier BK, et al. Results of an office-based training program in clinical breast examination for primary care physicians. J Cancer Educ 1996;11:25-31.

26. Goldstein MG, Niaura R, Willey C, et al. An academic detailing intervention to disseminate physician-delivered smoking cessation counseling: smoking cessation outcomes of the Physicians Counseling Smokers Project. Prev Med 2003;36:185-96.

27. Hulscher MEJL, Wensing M, van der Weijden T, Grol R. Interventions to implement prevention in primary care. Cochrane Database System Rev 2001; 1:CD000362.

28. Stevens SA, Cochburn J, Hirst S, Jolley D. An evaluation of educational outreach to general practitioners as part of a statewide cervical screening program. Am J Public Health 1997;87:1177-81.

29. Young JM, Ward JE. Randomised trial of intensive academic detailing to promote opportunistic recruitment of women to cervical screening by general practitioners. Aust N Z J Public Health 2003;27: 273-81.

30. Weller D, May F, Rowett D, et al. Promoting better use of the PSA test in general practice: randomized controlled trial of educational strategies based on outreach visits and mailout. Fam Pract 2003;20:65561.

31. Sheinfeld Gorin S, Gemson D, Ashford A, et al. Cancer education among primary care physicians in an underserved community. Am J Prev Med 2000; 19:53-58.

32. Dickey LL, Gemson DH, Carney P. Office system interventions supporting primary care-based health behavior change counseling. Am J Prev Med 1999; 17:299-308.

33. MacDonald CJ, Hui SL, Smith DM, et al. Reminders to physicians from an introspective computer medical record: a two-year randomized trial. Ann Intern Med 1984;100:130-8.

34. Austin SM, Balas EA, Mitchell JA, Ewigman BG. Effect of physician reminders on preventive care: meta-analysis of randomized clinical trials. Proc Annu Symp Comput Appl Med Care 1994;121-4.

35. Litzelman DK, Dittus RS, Miller ME, Tierney WM. Requiring physicians to respond to computerized reminders improves their compliance with preventive care. J Gen Intern Med 1993;8:311-7.

36. Curry SJ, Emmons KM. Theoretical models for predicting and improving compliance with breast cancer screening. Ann Behav Med 1994;16:302-16.

37. Pignone M, Harris R, Kinsinger L. Videotape-based decision aid for colon cancer screening. Ann Intern Med 2000;133:761-9.

38. Curtis P, Varenholt JJ, Skineer B, Addison L, Resnick J, Kebede M. Development of a Pap smear quality-assurance system in family practice. Fam Med 1993;25:135-9.

39. Winichkoff RN, Coltin KL, Morgan MM, Buxbaum RC, Barnett GO. Improving physician performance through peer comparison feedback. Med Care 1984; 22:527-34.

40. Tierney WM, Hui SL, MacDonald CJ. Delayed feedback of physician performance versus immediate reminders to perform preventive care. Med Care 1986;24:659-66.

41. Honda K, Sheinfeld Gorin S. A model of stage of change to recommend colonoscopy among urban primary care physicians. Health Psychol 2006;25:6573.

42. Azjen I. Fishbein M. Understanding attitudes and predicting social behavior. Englewood Cliffs (NJ): Prentice-Hall; 1980.

43. Bandura A. Social foundations of thought and action: a social cognitive theory. Englewood Cliffs (NJ): Prentice-Hall; 1986.

44. Bouton ME. A learning theory perspective on lapse, relapse, and the maintenance of behavior change. Health Psychol 2000;19:57-63.

45. Gemson DH, Elinson J. Cancer screening and prevention: knowledge, attitudes, and practice of New York City physicians. NY State J Med 1987;87: 643-5.

46. Neugut AI, Timony D, Murray TI. Colorectal cancer: differences between community and geographically distant patients seen at an urban medical center. Dis Colon Rectum 1991;30:64-8.

47. McCord C, Freeman HP. Excess mortality in Harlem. N Engl J Med 1990;322:173-7.

48. Murray DM. Design and analysis of group-randomized trials. New York: Oxford University Press; 1998.

49. Sheinfeld Gorin SN, Weirich TW. Innovation use: performance assessment in a community mental health center. Hum Rel 1995;48:1427-53.

50. Bandura A. Social foundations of thought and action: a social cognitive theory. Englewood Cliffs (NJ): Prentice-Hall; 1986.

51. Azjen I, Fishbein M. Understanding attitudes and predicting social behavior. Englewood Cliffs (NJ): Prentice-Hall; 1980.

52. Dickey LL, Gemson DH, Carney P. Office system interventions supporting primary care-based health behavior change counseling. Am J Prev Med 1999; 17:299-308.

53. Anderson WF, Jatoi I, Devesa SS. Distinct breast cancer incidence and prognostic patterns in the NCI's SEER program: suggesting a possible link between etiology and outcome. Breast Cancer Res Treat 2005;90:127-37.

54. Pathak DR, Osuch JR, He J. Breast carcinoma etiology: current knowledge and new insights into the effects of reproductive and hormonal risk factors in 
black and white populations. Cancer 2000;88: 1230-8.

55. McPherson K, Steel CM. Dixon JM. ABC of breast diseases. Breast cancer-epidemiology, risk factors, and genetics. BMJ 2000;321:624-8.

56. Martin AM. Weber BL. Genetic and hormonal risk factors in breast cancer. JNCI 2000;92:1126-35.

57. Laden F, Hunter DJ. Environmental risk factors and female breast cancer. Annu Rev Public Health 1998; 19:101-23.

58. Velentgas P, Daling JR. Risk factors for breast cancer in younger women. JNCI Monogr 1994;15-24.

59. CDC. Put prevention into practice. Available from: http://www.os.dhhs.gov:81/PPIP/ and http://www. emerson.edu. Accessed July 30, 2004.

60. Griffith HM, Dickey L, Kamerow DB. Put prevention into practice: a systematic approach. L Public Health Management Pract 1995;1:9-15.

61. May DS, Kiefe CI, Funkhouser E, Fouad MN. Compliance with mammography guidelines: physician recommendation and patient adherence. Prev Med 1999;28:386-94.

62. Meade CD, Diekmann J, Thornhill DG. Readability of American Cancer Society patient education literature. Oncol Nurs Forum 1992;19:51-5.

63. National Institutes of Health, NCI. National Ambulatory Medical Care Survey (NAMCS). Available from: www.cdc.gov/nchs/. Accessed November 26, 2002.

64. National Institutes of Health, NCI. Survey of physicians' attitudes and practices in early cancer detection. Healthy People 2010. Available from: http:// www.healthypeople.gov/. Accessed November 26, 2002.

65. Sheinfeld Gorin S, Jacobson J. Diet and breast cancer surveillance behaviors among Harlem women. Ann NY Acad Med 2001;952:153-60.

66. Wolfinger R, O'Connell M. Generalized linear mixed models: a pseudo-likelihood approach. J Stat Comput Simul 1993;48:223-43.

67. Witte JS, Greenland S, Kim LL, Arab L. Multilevel modeling in epidemiology with GLIMMIX. Epidemiol 2000;11:684-8.

68. Cohen J, Cohen P. Applied multiple regression/correlation analysis for the behavioral sciences. Hillsdale (NJ): Lawrence Erlbaum Associates: 1983; p. 275-300.

69. Coughlin SS, Uhler RJ, Bobo JK, Caplan L. Breast cancer screening practices among women in the United States, 2000. Canc Causes Control 2004;15: 159-70.

70. Fullilove RF, Fullilove ME, Northridge ME, et al. Risk factors for excess mortality in Harlem. Findings from the Harlem Household Survey. Am J Prev Med $1999 ; 16: 22-8$.
71. Medicare Part B Preventive Services. Available from: http://cms.hhs.gov. Accessed July 6, 2005.

72. Sheinfeld Gorin S. The political economy of health promotion. In: Sheinfeld Gorin S, Arnold J, editors. The handbook of health promotion. St. Louis: Mosby Year Book; 1998.

73. Turner B, Myers RE, Hyslop T, et al. Physician and patient factors associated with ordering a colon evaluation after a positive fecal occult blood test. J Gen Intern Med 2003;18:357-63.

74. Montano DE, Phillips WR, Kasprzyk D. Explaining physician rates of providing flexible sigmoidoscopy. Cancer Epidemiol Biomark Prev 2000;9:665-9.

75. Hawley ST, Levin B, Vernon SW. Colorectal cancer screening by primary care physicians in two medical care organizations. Cancer Detect Prev 2001;25: 309-18.

76. Zapka JG, Puleo E, Vickers-Lahti M, Luckmann R. Healthcare system factors and colorectal cancer screening. Am J Prev Med 2002;23:28-35.

77. Lerner BH. The breast cancer wars: hope, fear and the pursuit of a cure in twentieth-century America. New York: Oxford University Press; 2001.

78. Klausner RD. Mammography screening for women ages 40-49. Statement before the Subcommittee on Labor, Health and Human Services, Education and Related Agencies. February 5, 1997. Available from: http://deainfo.nci.nih.gov. Accessed January 30, 2004.

79. Sheinfeld Gorin S, New York Physicians Against Cancer (NYPAC). Disseminating colorectal cancer screening guidelines to primary care physicians in underserved communities. Presentation to the Society for Behavioral Medicine, 2005.

80. Collaborative Group for COMMIT Trials. Community Intervention Trial for Smoking Cessation (COMMIT): I. Cohort results from a 4-year community intervention. Am J Public Health 1995;85: 1983-92.

81. Myers RE, Turner B, Weinberg D, et al. Complete diagnostic evaluation in colorectal cancer screening: research design and baseline findings. Prev Med 2001;33:249-60.

82. Ganz PA, Farmer MM, Belman M, et al. Improving colorectal cancer screening rates in a managed care health plan: recruitment of provider organizations for a randomized clinical trial. Cancer Epidemiol Biomark Prev 2003;12:824-9.

83. Myers RE, Fishbein G, Hyslop T, Hauck WW, Kutch M, Grana JR, Schlackman N. Measuring complete diagnostic evaluation in colorectal cancer screening. Cancer Detect Prev 2001;25:174-82.

84. Gordon NP, Hiatt RA, Lampert DI. Concordance of self-reported data and medical record audit for six cancer screening procedures. JNCI 1993;85:566-70. 